\title{
The recreational potential for wastelands as well as users' preferences for wasteland aesthetics. Case study of Warsaw, Poland
}

\author{
Beata J. Gawryszewska ${ }^{1, *}$, Anna Wilczyńska ${ }^{1}$, Maciej Łepkowski ${ }^{1}$, Ryszard Nejman ${ }^{1}$, and \\ Martyna Cziszewska ${ }^{1}$ \\ ${ }^{1}$ Warsaw University of Life Sciences, Department of Horticulture, Biotechnology and Landscape \\ Architecture, Department of Landscape Art, 02-787 Warsaw, 166 Nowoursynowska St., Poland \\ (all of Authors)
}

\begin{abstract}
Urban wastelands may often be perceived as dysfunctional and unattractive, however they always seem to have environmental and sociological values, which encourage people to act spontaneously in their use. Undeveloped areas are important places in the structure of inhabiting landscape as a substitute for "natural" landscape. Therefore, the aim of the paper is to describe residents' aesthetical preferences for urban wasteland according to the image (type of scenery) and function of this kind of urban greenery. The survey was carried out on 13 selected case studies of brownfields, neglected greenery and undeveloped areas in Warsaw. The users' aesthetical preferences as well as the behaviour of residents, which have been treated as a neighbourhood greenery, were examined and compared. A basis of the comparison was differences in the image of the visiting landscape, perceived as different types of scenery. The methods used included Visitor Employed Photography and territorial markers and a physical traces inventory. The results show the various recreational uses, thus the great potential of wasteland green areas. It also confirms the growing acceptability of free vegetation aesthetics, while also presenting differences in the choice of a particular scenery by different groups of users.
\end{abstract}

\section{Introduction}

Due to its complex history and many spatial changes (destruction during World War II and the communist times) Warsaw is rich in various, undeveloped green areas, such as: brownfields, former railroad sidings or green spaces located within the Vistula valley. According to the researchers [1] wastelands that arose as a results of a natural succession in abandoned anthropological areas, have become important patches of a wilder nature in a broader context of urban green network. Moreover, these places, thanks to their recreational use are called "informal green spaces" [2] and have turned into not only natural but also social valuable resources [3] that provide all types of ecosystem services [4]. Regarding the theory of the structure of inhabited spaces, which shows the importance of the garden and

\footnotetext{
* Corresponding author: beata_gawryszewska@sggw.pl
} 
the surrounding landscape for owners and their values, urban gardens and wastelands seems to work as an equivalent of it, where urban inhabitants can act according to their needs and preference [5] while creating their surrounding.

Taking into consideration the aspects of the "inhabited spaces theory" as well as the commonly repeated conviction about the uselessness and ugliness of these kinds of spaces [1] and on the other hand observing residents acting spontaneously in wastelands areas, the authors have notices the need for a reflection on the aesthetical aspects and contemporary use of wastelands. Users seem to be "guided" by their personal aesthetical preferences when choosing and using particular areas (so called types of sceneries) of wastelands. Therefore, for the purpose of presented study, the authors answered following questions:

- what kind of aesthetical preferences are possible to distinguish in the presented case studies? What is their characteristic?

- what kind of use is specific for particular wastelands?

- is there dependency between aesthetic preferences, places and ways of use?

- are particular types of sceneries the cause of exclusiveness and the division of user groups?"

\section{Material and methods}

The presented research was based on 13 case studies of urban wastelands that were chosen according to the following criteria: neglected, abandoned or undeveloped green areas, located within the administrative borders of Warsaw, designated (in spatial plans) to be developed as public green spaces, areas located in the close vicinity of residential buildings, both existing and planned. The important aspect was a feasible number of case studies, to assure detail of the research. The chosen areas represent three groups, according to their location: Brownfields and ruins (including abandoned sports facilities); Neglected plots partially developed; and undeveloped areas in the river valley.

In order to study landscape aesthetical preferences and their connection with users' activities, a three-step approach was chosen:

1) The Visitor Employed Photography (VEP) method to specify the aesthetical preferences of respondents;

2) An inventory of physical traces and territorial marks to study ways of use;

3) A comparison of the aesthetical preferences and ways of use.

The research was carried out in the winter (Jan. 10 to Mar. 10 2018), being the first part of the research planned to be carried out during the period of the four seasons (until Dec.2018).

\subsection{Visitor Employed Photography (VEP) method}

To study aesthetical preferences, the VEP method [6] was chosen. The method originally developed for national parks areas [7], and was adapted for research in an urban landscape [8]. The adaptation for the presented study was based on the research carried out in Hibiya park in Tokyo [9], however instead of using GPS transmitters and cameras, smartphones with "MyTracks" software were used. This change resulted in a more precise information about the location of each picture that was taken by respondents. It also enabled registering the path taken by each respondent.

The respondents were a group of 25 people (Warsaw residents) including $56 \%$ women and $44 \%$ men. Eight people were 19-24 years old, ten of them were 25-34 years old, three $35-44$, and four of them were $45-55$ years old. These age groups are representative and typical for inhabitants living in residential areas in the closest vicinity of wastelands.. The respondents were asked to take one walk in each of the 13 case studies. They were asked to take a photo of everything that seemed "beautiful" or "interesting" for them (without the number of photos). KMZ files from the smartphones (with the routes of the walks and the 
photos with their geolocation) were used as layers on a WMS map in QGIS (open source software) and in Google Earth for further analyses.

In the first step of the presented study, all of the photos were examined by the authors and then, grouped in terms of similarity, in order to clearly specify the so called "types of sceneries". Later, existing types of scenery were mapped. Finally, as the types of scenery were clearly chosen and mapped, a chart of characteristics was created for each case study showing the number of photos taken per type of scenery. The summarized number of taken photos was an indicator in assessing the landscape preferences of respondents as a representative group [9].

\subsection{Physical traces and territorial markers inventory}

Territorial markers [10] and physical traces [11] are defined as indicators of the presence of users in anarea. Additionally, they are described as signs or even objects of everyday use, that are supposed to inform about the territory of particular user(s). For example, graffiti was the first type of territorial mark to be described [12]. According to previous studies [13,14] territorial markers (temporary low-budget buildings, the leftovers from neaks and habitats of the homeless etc.) and traces (informal paths, fireplaces, rubbish, etc.) signalise the borders of so called territorial domains (e.g. private gardens, courtyards, public spaces etc.) in the structure of an inhabited landscape.

In the presented study the authors have implemented territorial markers and physical traces inventory and treat them as indicators of functions and activities corresponding to users' needs and preferences. All markers and traces were photographed, saved as GIS data, by "MyTracks" software, and later mapped. The study was carried out by the authors.

\subsection{Comparative study}

The aim of the two previous steps $(2.1,2.2)$ was to study the preferences of two groups of users: 1 / arepresentative group of potential users - chosen respondents - to show aesthetical preferences; 2 / everyday users of the space ( their territorial markers) - to show preferences for their ways of use and the chosen places to act. In this step the authors compared two previous steps in order to look for dependencies between the places of activities, the ways of their use and aesthetical preferences (Table 1, Fig 2).

\section{Results}

In the first step 325 walks were registered ( 25 respondents x 13 surveyed areas).

3915 photos were taken from which 2012 were defined as scenery pictures based on 3 criteria: wide shot, at least two foreground, and the presence of the sky in the frame. The remaining 1903 pictures showed mostly details of the landscape (branches etc.) so it was not possible to compare them with ways of use. In the next step scenery pictures were grouped into so called "types of sceneries" according to: $1 /$ the density and height of the vegetation and 2/ the presence of a particular object in the center of the image (it was clear that the respondent wanted to show this element, that is why except for greenery, the remains of buildings, water and shoreline were taken under consideration).

In the second step territorial markers and physical traces in all 13 surveyed areas were inventoried, named and grouped:

\section{Territorial markers:}

-graffiti - murals, tags, stickers, inscriptions and similar signs

-homeless habitations - makeshift homes, tents, yurts, huts and other shelters; 
-provisory furniture and other constructions - seats made of materials and elements available in the area, makeshift shelters, bridges, houses for animals etc.

\section{Physical traces:}

- trails and entries - informal paths and gates created by pedestrians and cyclists;

- firepits;

- rubbish - discarded garbage - the leftovers from meals or landfills from nearby areas.

The determination of types of sceneries shows the way respondents perceive and differentiate the wastelands' landscapes. The number of photos for each type of scenery indicates the value assigned by respondents. The types of sceneries and aesthetical preferences in the form and number of the photos taken per type of scenery are presented in Table 1. Based on the photos and the authors' inventory of the studied wastelands, the spatial disposition and area of types of sceneries were mapped (Fig.2.)

The highest rated type of scenery was a waterbody (25\%) which was the expected result. Next a light forest, a shoreline, an unmowed sward, loosely tree covered, the remains of buildings and walls, fluctuated around 10\%. The lowest rated type of scenery was "wilderness".
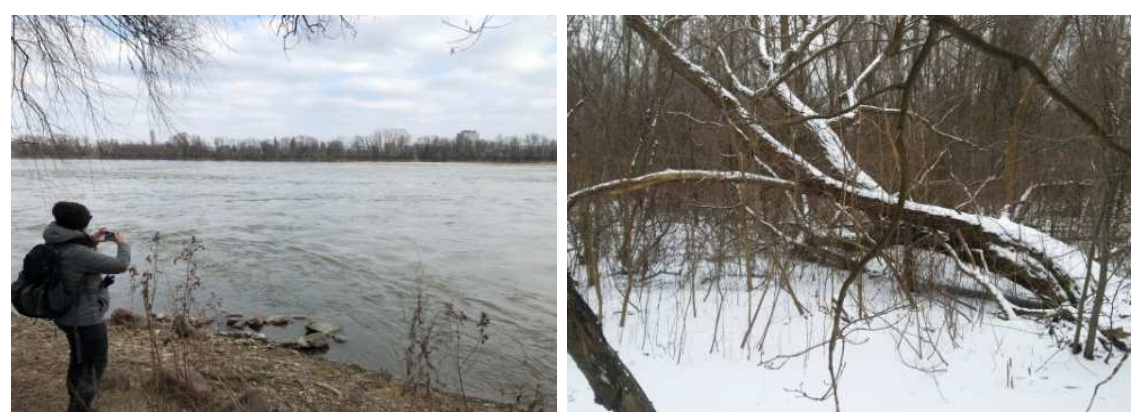

Fig. 1. The highest rated ("waterbody")- left and lowest rated ("wilderness") - right (BJ. Gawryszewska, A. Dudek).

The most frequently repeated territorial marker was rubbish (45), then more or less similar (between 10-22) provisory furniture and buildings, trails and firepits, and finally homeless habitations (2).

The most popular type of scenery for different ways of use is mowed grassland, loosely tree-covered, the remains of building and walls, and shorelines (14-17). The least is wilderness (0).

An interesting connection could be observed regarding highly rated scenery types (light forest, shoreline, unmowed sward, loosely tree covered, the remains of buildings and walls) and territorial markers / physical traces whose amount remains at an average level (around 10) for these preferred types of scenery (with the exception of ruins, where the presence of graffiti raises the indicator to 14 points).

There are two territoriality markers, graffiti and homeless habitations that were found in four specific sceneries only (loosely tree-covered, low thickets, mowed grassland and the remains of constructions or walls). It may explain the exclusiveness of the group of their users. 


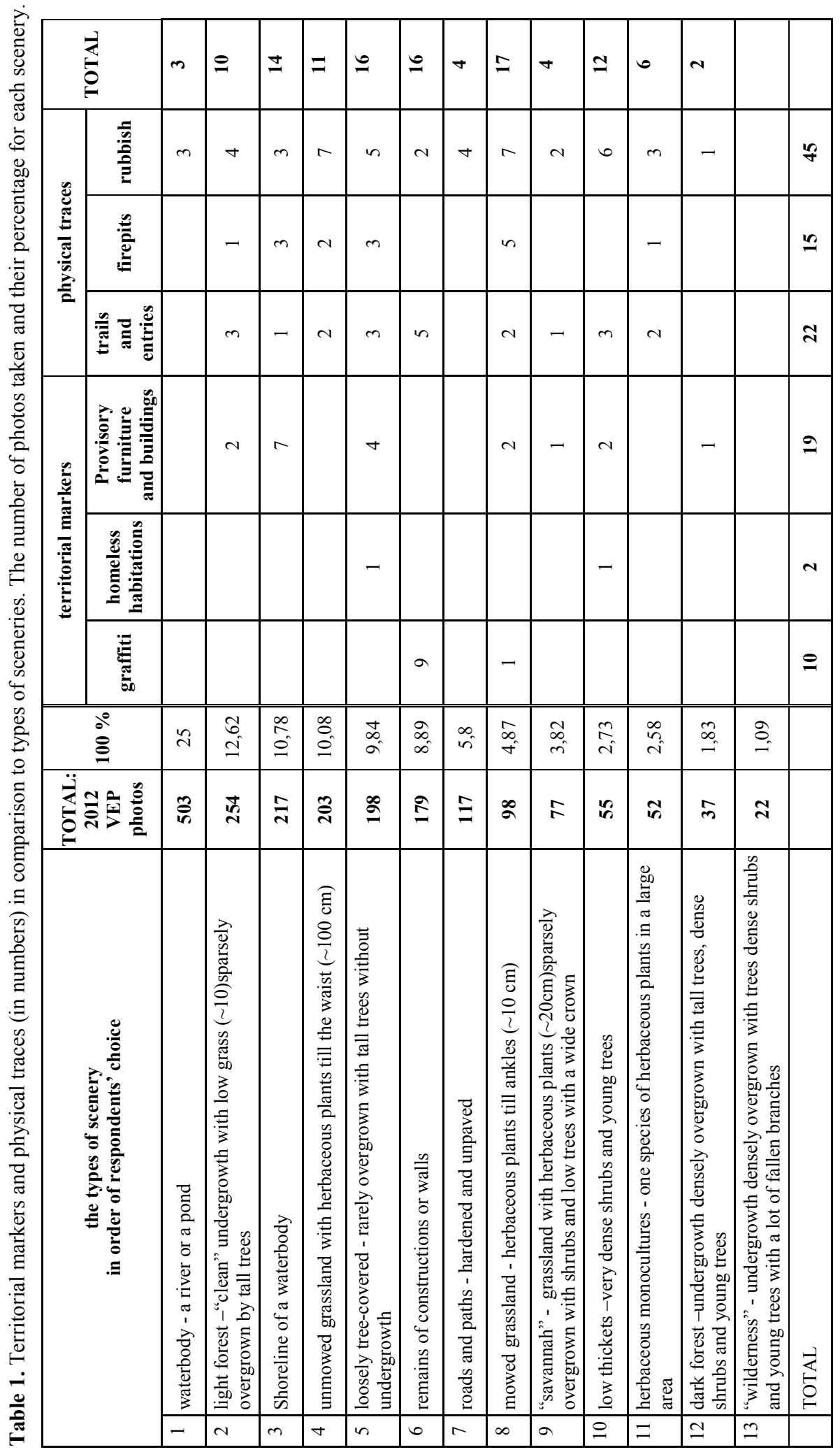



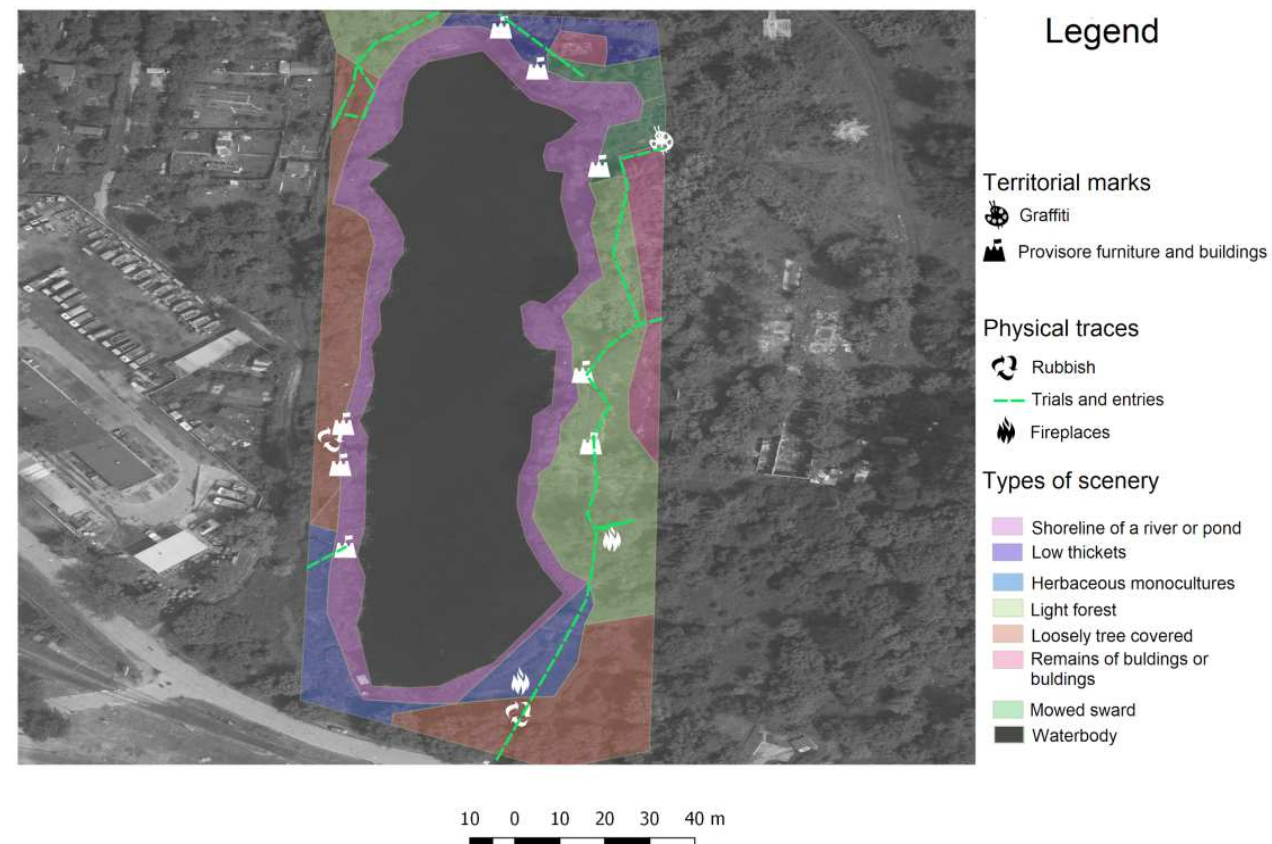

Fig. 2. Sample map showing the location of territorial markers and physical traces in relation to the scenery types for the "Kozia Górka" area (own study authors).

\section{Discussion}

After the comparison of results from the first two steps it is basically clear that users prefer these fragments of the studied areas, which have a lot of nature and greenery, yet at the same time are easily accessible and have a visible structure. The presence of tall trees with large amount of space in between them as well as open, unmowed grasslands and glades are an unquestionable advantage. Some studies prove that it is connected with users' preferences for vegetation structure $[15,16]$. Vegetation structures may be associated with an image of a "classic landscape" of an urban park (loose trees, small amount of undergrowth, open grassy areas). Researchers point out the connection of naturalness with a category of picturesqueness [17] - a specific proportion between wilderness, which is a synonym of chaos and danger and artificiality, which is an overrepresentation of human presence. Thus, the old category of picturesque nature returns in the new, more "naturalized" not only "nature imitating" version. However, according to the presented results and some studies still naturalness (at some extent), but not full "wilderness" is accepted and appreciated, [15]. Consequently, according to the presented results, in 13 case studies the preferred sceneries of the wastelands' landscape seems to a moderate degree, on which a space is not "overload" but balanced (between what is perceived as natural and anthropogenic). Similar conclusions have been drawn by the authors of research conducted in Japan and Australia [2]. Based on the results of territorial markers and traces inventory it is accepted and probably even to some extent preferred is the feeling that in a wasteland landscape, we are not alone [18] and we can freely use it like people who were here before us and left marks and traces. However, as previous and the presented research show, accessibility, which means semi-natural spaces is important for users and their preferences [1]. Additionally, according to researchers, simple 
interventions are a good method to increase the number of users in wastelands, boarding a spectrum of activities and users [20].

\section{Conclusions - the recreational potential and users' preferences for wastelands}

The presented results show that although wastelands seem to be abandoned, in fact they are used intensively. The first and most common way of their use is recreation, but we can observe more illegal-like actions (garbage) or habitation (for the homeless). It is interesting to note, that people perceive wastelands as a kind of inclusive space, where many forbidden "regular" urban greenery activities are accepted. Therefore, wastelands operate as a complementary part of the urban green infrastructure. Moreover, its closeness to residential areas plays an important role in the above-mentioned structure of inhabited urban space, being 'handy' open green space. Because of a variety of territorial markers found in the studied wastelands it may be concluded that they have a potential for recreation. James J. Gibson claimed that the basis for valuing and giving meaning to places were affordances (Gibson). The most frequently used sceneries, like mowed sward seem to have many different affordances, and consequently meanings for their users. That makes them an important part of green infrastructure not only because of their ecological aspects, but their value for urban inhabitants.

Regarding aesthetical preferences, the most preferred sceneries were slightly different than the most frequently used. Waterbodies, for example, are the most admired yet at the same time are also impossible to use, however the shoreline is already much more attractive for activities. Mowed grasslands, and loosely tree-covered areas, groups of shrubs or the remains of buildings and constructions are preferred both for use and for admiration. The reason may be the image, which recalls romantic parks or even gardens. The sceneries preferred by respondents are very diverse, covering almost all possible forms of greenery that may indicate a growing acceptability of free vegetation aesthetics. An important aspect is the accessibility of the space, the possibility to enter and and explore it.

Converselyly, "wilderness" densely covered with "tall trees and undergrowth with a lot of rotting wood" was empty of use markers and the least admired. It appears that it is still perceived as unattractive and useless. Therefore, high preferences for water scenery and low preference of "wilderness" proclaim that users prefer open spaces, with deep visibility. At the same time we can observe the exclusiveness of the sceneries, chosen by specific groups of users - the homeless and graffiti artists.

What is important to keep in mind is the fact that wastelands that are perceived as informal green spaces are for many people not only places of recruitment but also of refuge and habitation. Transforming a wasteland into a "classical", intensively managed urban green could result in the effect of gentrification for various social groups (e.g. homeless) [16].

This work is implemented as part of the project "Inventory and valorisation of selected degraded and polluted areas in Warsaw - natural and social potential of wasteland", co-financed under the Operational Program Infrastructure and Environment 2014-2020 2.5 "Improvement of the quality of the urban environment", a project commissioned by the Zarząd Zieleni M.St. Warszawy (Department of Urban Greenery, Municipality of Warsaw).

\section{References}

1. M. Łepkowski, R. Nejman, A. Wilczyńska, Proceedings of 5th Fábos Conference on Landscape and Greenway Planning, Budapest, Hungary (2016) 
2. C.D.D. Rupprecht, J.A. Byrne, Urban For Urban Green, 13.4 (2014)

3. P. Tredici, Places, (2014) [online] [access: 30.04.2018] https://placesjournal.org/article/the-flora-of-the-future/

4. B.J. Gawryszewska, A. Wilczyńska, M. Łepkowski, Growing in Cities : Interdisciplinary Perspectives on Urban Gardening Conference, Basel, UAS (2016)

5. B.J. Gawryszewska, A. Wilczyńska, Architecture for the Society of Knowledge, Education for research, research for creativity, WA PW, Warszawa (2016)

6. G.J. Cherem, B.L. Driver, J Leis Res, 15 (1983)

7. G.J. Cherem, Proceedings of Aesthetics Opportunity Colloquium, Logan, UT(1973)

8. K.M. Haywood, J. Travel Res., 29.1 (1990)

9. K. Sugimoto, Procedia - Social and Behavioral Sciences, 21 (2011)

10. D. Ley, R. Cybriwsky, Ann. Assoc. Am. Geogr., 64.4 (1974)

11. E. J. Webb, D. T. Campbell, R. D. Schwarz \& L. Sechrest, Unobtrusive measures Thousand Oaks, CA: Sage (2000)

12. P. A. Bell, T. C. Greene, J. D. Fisher \& A. Baum, Environmental psychology, New York Harcourt College Publishers (2001)

13. B.J. Gawryszewska Revitalising Built Environments: Requalifying Old Places for New Uses, IAPS-CSBE and IAPS (2009)

14. E. Winiarska, Sztuka ogrodu Sztuka krajobrazu, 3(7) (2013)

15. L. K. Fischer, J. Honold, R. Cvejić, T. Delshammar, S. Hilbert, R Lafortezza, M. Nastran, A. Busse Nielsen, M. Pintar, A. van der Jagt, I. Kowarik, Global Environ Chang 49(35) (2018)

16. C.D.D. Rupprecht, J.A. Byrne, Informal urban green space as anti-gentrification strategy? 2017. doi:10.17605/OSF.IO/MFA4W

17. M. Ignatieva, G.H. Stewart, C. Meurk, Landscape Ecol Eng (2011)

18. S. Maruthaveeranab, C. C. Konijnendijkvan den Boschac, Urban For Urban Green, 13.1 (2014)

19. J. Gibson, The ecological approach to visual perception, Lawrence Erlbaum Hillsdale, NJ. 8.

20. A.-L. Unt, S. Bell, Urban For Urban Green, 13 (2014) 